\title{
Preoperative Detection of Novel Predictors for Lymph Node Metastasis in Early Colorectal Cancer
}

\author{
Jung Wook Huh • Young Jin Kim
}

Received: 4 February 2011 / Accepted: 10 August 2011 / Published online: 10 September 2011

(C) 2011 The Society for Surgery of the Alimentary Tract

Dear Editor,

We thank Dr. Shukla and colleagues for their interest in our paper. ${ }^{1}$ Due to the recent advances in endoscopic techniques, $\mathrm{T} 1$ or $\mathrm{T} 2$ tumors may potentially be cured by non-invasive resection of the tumor with the appropriate selection of patients. Preoperative detection of novel predictive factors for lymph node metastasis from early colorectal cancer may be the most important issue for obtaining a better prognosis in this group of patients. Unfortunately, the recent preoperative clinical studies that have employed imaging modalities or histopathological examination have fallen short of our expectations in terms of detecting high risk factors in a preoperative setting.

In last year's August issue of the Journal of Gastrointestinal Surgery, ${ }^{2}$ we observed that the incidence of lymph node metastasis for all the patients with early colorectal cancer was a considerable figure at $21.0 \%$ (14.5\% for $\mathrm{T} 1$ and $23.9 \%$ for $\mathrm{T} 2$ ). As we mentioned in our study, the presence of lymphovascular or perineural invasion was associated with lymph node metastasis, and the latter was the only independent factor that could predict the survival of patients with early tumor. Therefore, the preoperative identification of high risk factors for lymph node metastasis in patients with early tumor cannot be emphasized too strongly. We agree with the comment of Dr. Shukla and colleagues that both lymphovascular and perineural invasion are best detected by pathological examination after surgical resection, and no imaging modalities that can detect them are currently available. Furthermore, developing new technologies for enhancing the accuracy of detecting these high risk factors in preoperative biopsied specimens may be essential in the future clinical setting. New research in the field of pathology as well as radiology is needed to facilitate the evaluation of the high risk factors for survival in patients with colorectal cancer in the preoperative setting.

\section{References}

1. Shukla PJ, Ma J, Yantiss RK, Milsom JW. The clinical significance of lymphovascular \& perineural invasion in patients with colorectal cancer. J Gastrointestinal Surg 2011 (in press).

2. Huh JW, Kim HR, Kim YJ. Lymphovascular or perineural invasion may predict lymph node metastasis in patients with $\mathrm{T} 1$ and $\mathrm{T} 2$ colorectal cancer. J Gastrointestinal Surg 2010;14:1074-1080.

\footnotetext{
J. W. Huh · Y. J. Kim $(\bowtie)$

Department of Surgery, Chonnam National University Hwasun

Hospital and Medical School,

160 Ilsimri, Hwasun-eup, Hwasun-gun, Jeonnam,

519-809 Gwangju, South Korea

e-mail: jwhuh@chonnam.ac.kr 